\section{LOS INDISCIPLINADOS}

\author{
LA IMAGEN COMO VECTOR DE \\ PENSAMIENTO EN LAFOTOGRAFÍA \\ ARTÍSTICA LIMEÑA EN LA DÉCADA DE 1990
}

The undisciplined. The image as a vector of thought

in Lima's artistic photography in the 1990s

\section{RESUMEN}

El presente texto plantea como hipótesis que la generación de fotógrafos que trabajó en el campo artístico en el Perú de los años noventa se caracterizó por un doble movimiento crítico. Por el lado crítico-deconstructivo, deslindó la práctica fotográfica de los principios del modernismo americano que los fundadores de la "Secuencia Foto Galería" habían importado y adaptado al contexto peruano (limeño) hacia fines de los setenta. Por el lado crítico-constructivo, expandió los límites de la práctica fotográfica abandonando la primacía de la autonomía de la imagen y priorizando la construcción de dispositivos estéticos visuales. Así, a través del análisis de cinco casos -Roberto Huarcaya, Flavia Gandolfo, Luz María Bedoya, Milagros de la Torre y Juan Enrique Bedoya- este ensayo muestra la formación de un campo fotográfico artístico en el que la fotografía no opera como representación de la realidad sino como su problematización. Es decir, como vector de pensamiento.

\section{ABSTRACT}

The hypothesis of the present text suggests that the generation of photographers who worked in the artistic field in Peru in the 1990s was characterized by a double critical movement. On the critical-deconstructive side, separated the photographic practice from the principles of American modernism that the founders of the Photo Gallery Sequence had imported and adapted to the Peruvian context (Lima) towards the end of the 70's. On the critical-constructive side, expanded the limits of photographic practice, leaving the primacy of the autonomy of the image and prioritizing the construction of visua aesthetic devices. Thus, through the analysis of five cases -Roberto Huarcaya, Flavia Gandolfo, Luz María Bedoya, Milagros de la Torre and Juan Enrique Bedoya- this essay shows the formation of an artistic photographic field in which photography does not operate as a representation of the reality but as its problematization. That is,
Palabras clave:

Fotografía peruana

contemporánea,

generación del noventa,

Roberto Huarcaya,

Flavia Gandolfo,

Luz María Bedoya,

Milagros de la Torre,

Juan Enrique Bedoya

\section{Key words:}

Contemporary Peruvian

photography,

90s generation,

Roberto Huarcaya

Flavia Gandolfo,

Luz María Bedoya,

Milagros de la Torre,

Juan Enrique Bedoya
Alejandro León Cannock

https://orcid.org/0000-0002-4333-2000

Fotógrafo e investigador. Doctorando en Práctica y Teoría de la Creación Artística y Literaria en la Escuela Nacional Superior de Fotografía en Arles y en la Universidad de Aix-Marsella, Francia.

cannock@gmail.com

\section{INTRODUCCIÓN. TRES “ENTRADAS EN} ARTE" PARA LA FOTOGRAFÍA

01. A diferencia de lo que ocurre con la pintura o la escultura, el reconocimiento universal del carácter artístico de la imagen fotográfica es un hecho histórico reciente. Como afirma Rouillé (2005, p. 31), el aparato fotográfico nace como una herramienta destinada a la producción de representaciones técnicas útiles para diversos fines (científicos, sociales, políticos y también artísticos), pero que no tienen un valor artístico intrínseco. Recordemos la forma lapidaria en que, en su famosa crítica para el Salón de 1859, Baudelaire (1996) le negó a la fotografía el ingreso al ámbito del arte por tratarse de una máquina que solo era capaz de reproducir la apariencia de la naturaleza, por tanto, que estaba desconectada de las auténticas fuentes de la creación: la sensibilidad y la imaginación. Por ello, su rol debía quedar muy claro: ser la "sirvienta de las artes y de las ciencias" (p. 233).

02. A pesar de este origen instrumenta subordinado, la imagen fotográfica pretendió, desde sus primeros días, ser considerada también como una obra de arte. Esta es una historia muy conocida sobre la que no vamos a volver ahora1. Solo nos interesa señalar que e "devenir artístico" de la fotografía no ha seguido un único camino. Los esfuerzos realizados a largo de estos casi 200 años han estado determinados por las modificaciones en los criterios demarcatorios que definen lo que es arte y lo que no. Pues, como han señalado múltiples autores (Danto, 1999; Belting, 1987; Smith

Algunos estudios importantes al respecto: Alloway, 1970; Kahmen, 1974; Scharf, 1968; Chevrier, 2003; Fried, 2013
2012; Kuspit, 2006) el arte no posee una esencia eterna e inmutable. Por tanto, para comprender las diversas "entradas en arte" de la fotografía es necesario tener en cuenta las condiciones de "artisticidad" dominantes en los distintos paradigmas que existen en la Historia del arte (Heinich, 2014, pp. 30-38). Siguiendo esta lógica, se puede afirmar que han existido tres "entradas en arte" principales en la Historia de la fotografía: i) el movimiento pictorialista fundado durante las últimas décadas del siglo XIX (paradigma clásico / heteronomía del medio); ii) las vanguardias modernistas establecidas en la primera mitad del siglo XX (paradigma moderno / autonomía del medio); y iii) las prácticas artísticas posteriores a los años 60 (paradigma contemporáneo / pluralismo post-medial).

03. De forma equivalente, en la Historia de la fotografía peruana se pueden determinar tres momentos en los que se desarrolla de forma consciente una práctica fotográfica con pretensiones artísticas. En primer lugar, durante las décadas inaugurales del siglo XX se instaló en la región sur andina del Perú (en Arequipa y Cusco) un movimiento fotográfico que siguió los parámetros estilísticos de la fotografía de salón y del pictorialismo. Sus representantes más destacados fueron los Hermanos Vargas y los fotógrafos de la "escuela cusqueña", entre los que destacaron Juan Manuel Figueroa Aznar y, especialmente, Martin Chambi (Majluf y Villacorta, 1997, pp. 16-17; y, Cruz, del Valle, Hernández Calvo y Ramos, 2014, p. 98). En segundo lugar, entre los años 1960 y 1990 se formó una tradición de fotografía limeña que se inauguró a inicios de los años 60 con la presencia activa en la capital de fotógrafos 
como José Casals, Baldomero Pestana y Carlos "chino" Domínguez, pero que obtuvo su punto más alto de autoconciencia y reconocimiento artístico gracias a Billy Hare y Fernando La Rosa, fundador este último de la primera galería dedicada a la fotografía en el Perú: Secuencia Foto Galería (1977-1980)2. Ambos fueron herederos de los principios estéticos del tardo-modernismo místico de los fotógrafos estadounidenses Minor White y Aaron Siskind (Majluf y Villacorta, 1997, pp. 17-19; y, Cruz, del Valle, Hernández Calvo y Ramos, 2014, p. 290)3

04. La tercera "entrada en arte" se da nuevamente en Lima a inicios de los años 90 sin duda una consecuencia más del centralismo que reinó en el país durante la segunda mitad del siglo XX-. Esta estuvo comandada por un grupo de fotógrafos que, influenciados por los cambios en el terreno de la fotografía y del arte a nivel global (posmodernismo, tecnologías digitales, giro icónico, mercantilización, etc.) y por la redefinición de las artes visuales en el Perú -debido a los cambios sociales que resultaron de la superación de los años de guerra interna y al nuevo contexto geopolítico en el que el país se insertó (Quijano, 2002; y, Del Valle y Villacorta, 1999)-, decidieron romper con el canon propuesto por el modernismo de Secuencia (Villacorta y Hernández Calvo 2002, p. 114; Majluf, 2006, p. 19; y, Villacorta y Trivelli, 2014). Con el objetivo de cartografiar las estrategias estéticas y conceptuales de esta nueva generación de "indisciplinados", en las siguientes páginas nos focalizaremos en el trabajo de cinco de sus representantes más

2 Secuencia Foto Galería se planteó institucionalizar la fotografía artística en el Perú: "Hace un tiempo un grupo de fotógrafos activos en la exploración creativa del medio, se reunió con la finalidad de difundir en el Perú el Arte Fotográfico y ayudar a resolver las muchas incomprensiones que este sufre" (Hare Montalbetti, 1977).

3 En el I Seminario de Arte Latinoamericano organizado por la Revista Kaypunku y el Museo de Arte Contemporáneo de Lima (9 de junio de 2016), titulado "Indocumentado: del negativo a la posfotografía", la investigadora Gabriela Germaná dio una conferencia que abordaba en detalle a la generación de fotógrafos vinculados a Secuencia: "Secuencia Foto Galería: los If emblemáticos: Juan Enrique Bedoya, Roberto Huarcaya Milagros de la Torre, Luz María Bedoya y Flavia Gandolfo4. Sin embargo, antes de ello es necesario presentar el escenario en el que desarrollaron su actividad. Nuestra hipótesis, al igual que lo afirma Lerner (2020, p. 11) es que hacia fines de los años 80 y a lo largo de toda la década del 90, el territorio de la fotografía artística limeña atravesó dos fenómenos importantes: su formalización y su expansión.

\section{NOTAS SOBRE LA CONSOLIDACIÓN DEL TERRITORIO DE LA FOTOGRAFÍA ARTÍSTL- \\ CA LIMEÑA EN LOS AÑOS 90}

\section{La formalización institucional}

05. La formalización refiere a la paulatina constitución de un territorio institucionalizado para la fotografía y, especialmente, para sus usos artísticos. Como han señalado Majluf y Villacorta (1997, p. 15), y López (2020, p. 19), el nacimiento del Consejo Nacional de Fotografía y del Instituto de Fotografía Artística entre los años 1988 y 1990 representó un intento importante de institucionalización de la fotografía peruana. Prolongando el argumento de estos autores, y a pesar de la prudente posición de investigadores como Zevallos Trigoso (pp. 11-12) quien, también apoyándose en Majlu y Villacorta (1997), y en Hernández Calvo y Villacorta (2002), afirma que se debe hablar de un campo "quizá en estructuración" (p. 12) sostendremos que la creación de ambas instituciones (CNF y IFA) significó el fin del periodo de formación de la tradición de la fotografía limeña (1960-1990) y, con ello, el inicio de su etapa de consolidación (1990-2010).

06. Este afianzamiento se efectuó gracias en la realización de eventos institucionales importantes: la creación de los ya mencionados CNF e IFA; la realización del Primer Coloquio Peruano de Fotografía (Universidad de Lima 1989)5; la organización de la exposición

4 López sostiene una hipótesis similar al afirmar que el ingreso a un "ánimo 'posmoderno' o 'conceptual'" se dio el acte peruano gracias a la actividad de estos cinco fotógrafos $(2020$, p. 40).

5 En aquel periodo también se intentó formalizar colectiva Fotografía peruana actual (1989) la publicación de las revistas Taxi foto (1995) y Portafolio. La revista de la imagen (1992); la creación del área de fotografía en el Instituto Antonio Gaudí (1993), dirigida por Billy Hare, Roberto Huarcaya y José Antonio Ramos6; la realización de la exposición Documentos: Tres décadas de la fotografía en el Perú (1960-1990 (Museo de Arte de Lima, 1997); la exhibición retrospectiva Billy Hare. Fotografías (Fundación Telefónica, 1997). En este resumen se debe incluir la participación de la fotografía en las Bienales Iberoamericanas de Lima $(1997,1999$ y 2002)7, en la VI Bienal de La Habana (1997), $y$ en dos exposiciones internacionales que abren y cierran dicha década, marcando un cambio generacional y estilístico importante: The Peruvians (Universidad Harding-Simmons, Estados Unidos, 1989) y Especies de Espacios: Extensiones y Metáforas de la Fotografía Contemporánea en Perú (PhotoEspaña, 1999)8.

07. La institucionalización de la fotografía limeña en la década de 1990 se concretiza, entonces, gracias al reforzamiento de un conjunto de elementos estructurales. (i) Los referentes. A la figura mundialmente reconocida de Martín Chambi se sumaron, gracias a su trabajo autoral y a su actividad pedagógica, Billy Hare y Fernando La Rosa. (ii) La educación. En las sociedades modernas el proceso de transmisión de conocimientos se realiza a través de la educación. Antes de la creación del área de fotografía del Instituto Gaudí, no existía un espacio formal dedicado a la investigación, a la enseñanza y a la difusión de la fotografía desde una perspectiva técnica, estética, teórica e histórica. (iii) El museo. Como señala Heinich (2014 pp. 210-231) la entrada al museo constituye el punto más alto en la escala de legitimación en el mundo del arte pues implica ingresar en la Historia. En tal sentido, el papel jugado por e

el campo de la fotografía en Arequipa a través de la realización de dos Bienales de fotografía (1989 y 1991) organizadas por Juan Carlos Belón Lemoine.

Esta escuela se convirtió en el Centro de la fotografía $y$, posteriormente, en el Centro de la imagen.

7 Para un análisis del fracaso de estas Bienales ver Biczel, 2017.

8 Sobre esta muestra itinerante ver Gras Balaguer (1999)
MALI no solo terminó de legitimar, como afirma Majluf(2006, p. 10) la existencia de una historia propia para la fotografía peruana ante los profesionales, sino también frente al gran público y a los coleccionistas. (iv) La investigación. Este es uno de los aspectos más débiles de la tradición artística en el Perú. No obstante, los números de la revista Taxi foto y Portafolio, sumados a la imprescindible investigación presentada en el catálogo de la exposición Documentos, impulsaron la reflexión sobre el medio fotográfico9. (v) La comunidad. Se puede afirmar, entonces, que durante los años 90 se afianzo, ad-portas del siglo XXI, el proceso por el que se había buscado crear una tradición de fotografía peruana conectando los años dorados de la fotografía sur andina de la primera mitad del siglo XX con la fotografía modernista limeña de la segunda mitad. A pesar del carácter "discontinuo" de dicha tradición (Majluf y Villacorta, 1997, p. 31), es innegable que en aquel contexto se formó un territorio de fotografía artística suficientemente estable como para permitir la emergencia de una generación de fotógrafos completamente renovada.

\section{La expansión ontológica}

08. Este proceso de formalización no implicó la imposición de un canon fotográfico, sino más bien el reconocimiento de su carácter plural (Bedoya, 2014, s/p). La consolidación institucional creó las condiciones para el encuentro entre fotógrafos con intereses diversos, para las discusiones públicas, para el intercambio de experiencias, para la creación colectiva, para la experimentación, etc. Estas dinámicas muestran que el campo fotográfico, lejos de cerrarse sobre sí mismo dogmáticamente para defender un estilo o una escuela, empezó a expandirse (Baker, 2005) explorando creativamente las diversas posibilidades que el medio ofrecía. En tal sentido, la generación

9 Luz María Bedoya señala que una de las principales limitaciones de la fotografía peruana es "la ausencia de un aparato crítico sostenido en el tiempo, que le devuelva una noción de sí mismo" (2006, s/p). Ver, también, Majluf, 2006, p. 11. Es justo indicar, sin embargo, que la investigación ha avanzado mucho en el siglo XX gracias a los valiosísimos trabajos de Jorge Villacorta y Andrés Garay 
de fotógrafos que emerge en los años 90 no se identifica con las prácticas modernistas de sus predecesores y se plantea como objetivo, para decirlo en términos de Deleuze y Guattari $(1978$, p. 31), crear una lengua revolucionaria (fotográfica) al interior de la lengua dominante. Estos dialectos heréticos incorporaron, como afirma López, "formas hibridas y géneros bastardos" (2020, p. 20) contribuyendo, en medio del proceso de institucionalización de la fotografía artística, también con su expansión, como han señalado Villacorta y Hernández Calvo (2002, pp. 116-117)10. Por ello, dicha formalización no debe confundirse con un proceso de disciplinamiento sino, aunque parezca paradójico, de "indisciplinamiento"11.

09. Para intentar comprender el carácter indisciplinado de estos fotógrafos nos gustaría señalar un aspecto que consideramos que tiene un peso más importante del que se le suele atribuir: su educación. Sus primeros aprendizajes fotográficos fueron autodidactas o en talleres informales. Esta precariedad educativa promovió la experimentación y evitó la formación de una escuela dogmática. Al mismo tiempo, los impulsó a buscar estudios en el exterior. Flavia Gandolfo estudió fotografía en la Universidad de Houston (Texas, Estados Unidos); Luz María Bedoya se formó en la New England School of Photography y en el School of the Museum of Fine Arts (Boston, Estados Unidos); Roberto Huarcaya, estudió cine y fotografía en el Instituto Italiano de Cultura y Fotografía en el Centro del Video y la Imagen (Madrid, España); Milagros de la Torre hizo un Bachillerato en el London College of Printing (Londres, Inglaterra). Juan

10 Esta generación no solo contribuyó con la expansión del campo de la fotografía, sino que, al hacerlo, impulsó también una renovación en las artes visuales en el Perú (Majluf, 2006, p. 24; y, Villacorta y Hernández Calvo, 2002, p. 115).

11 Luz María Bedoya encuentra en la lectura que hace Montalbetti (1980) de la serie Chorrillos de Mariella Agois un primer intento de romper con el modernismo. Es un trabajo, dice Bedoya, producido por una "mirada des-domesticada" (2006, s/p). En la misma línea, Bedoya (2018) afirma que la serie Artes y ensartes (1987), en la que el fotógrafo Roberto Fantozzi retrata paródicamente a la clase alta limeña, también muestra un distanciamiento 4
Enrique Bedoya no realizó estudios de fotografía en el extranjero, pero tuvo la oportunidad de pasar una larga estancia en Estados Unidos (1993-1994) gracias al International Fellowship Program, Mid America Arts Alliance (M.A.A.A.) del National Endowment for the Arts. Esto les permitió educarse visualmente en contexto en los que el modernismo había declinado y donde se había instalado, al menos desde fines de los 70, una visión postmoderna del arte y de la imagen. Bebieron, entonces, de una concepción del mundo que -parafraseando el título del célebre ensayo de Sekula (2004)había "desmantelado la modernidad"12. Esta referencia biográfica no es anecdótica pues nos permite constatar que estos fotógrafos aprendieron a usar y a pensar la imagen fotográfic ya no como un fin en sí mismo, como un medio autónomo a respetar -ya sea para representar el mundo exterior (variante documental) o para expres el mundo interior del artista (variante estética)13-, sino como un instrumento creativo -un medio y material como la pintura, el video el sonido- capaz de problematizar críticamente alguna dimensión de la realidad. Estos viajes de formación les permitieron tener, como man Gandolfo (2018)، Bedoya (2018) y De la Torre (2020), una comprensión experimental y conceptual de la fotografía14.

2 El desmantelamiento del canon modernista y su pertura epistemológica se concretó notablemente en a exposición Pictures comisariada por Douglas Crimp (1977), en la que participaron Tray Brantuch, Jack ongo, Philip Smith.

13 Esta doble función de la fotografía está en el centro de la concepción modernista promovida desde los Estados Unidos por John Szarkowski. Ver la exposición Windows and Mirrors (1964).

14 En la misma época en que la pictures generation afirmaba en los Estados Unidos un uso indisciplinado de la imagen, en el Perú se establecía la tradición modernista de Secuencia. No obstante, un sector de las artes plásticas peruanas entre fines de los 70 e inicios de los 90 ya hacía un uso posmoderno de la imagen fotográfica similar al de la pictures generation. Esto muestra el carácter diacronico de la historia. Esta otra historia del "devenir artístico" de la fotografía es clave y requeriria un estudio particular. Para una aproximación a esta problemática ver Quijano (2002) donde señala la existencia de esta "nueva genealogía de la imagen fotografica" (p. 57), representada por artistas plasticos como Fernando 'Coco' Bedoya, Armando Williams, Francisco Mariotti, Jesús Ruiz Durand, Guillerm
10. Pero hay un aspecto que es, incluso, tal vez más relevante. Antes de educarse fotográficamente, todos tuvieron una formación disciplinaria universitaria no artística. Huarcaya estudió psicología; Luz María Bedoya, Literatura y lingüística; Gandolfo, Historia; De la Torre, Ciencias de la comunicación; y, Juan Enrique Bedoya, Derecho. Mi hipótesis es que esta exterioridad académica les permitió no tener el mismo respeto que un fotógrafo de formación (o de profesión) tiene hacia la fotografía. Pero principalmente, los llevó a ver en la fotografía algo más que un simple medio técnico de representación del mundo. La fotografía se afirmaba como un lenguaje tan legítimo como el verbal para pensar la realidad. Por ello, el hecho de provenir de disciplinas universitarias en las que se promueve la investigación, la producción y la difusión de conocimiento, permitió que estos fotógrafos incorporen en su práctica artística una dimensión crítica esencial.

11. La consecuencia directa que se desprende de este contexto formativo es, como ya sugerimos, la ruptura con el canon modernista de la fotografía limeña. Los proyectos de esta nueva generación no son autorreferenciales $y$ no tienen, por tanto, ni como temática a la forma de lo fotográfico ni como objetivo a la expresión de la subjetividad. No usan la fotografía para traducir en formas visuales la experiencia de fotógrafo. Pero este rechazo no los hace reple garse sobre la orilla opuesta al formalismo: el documental. Su ruptura también se efectuó contra el trabajo de los fotorreporteros y de los documentalistas que, en el mismo periodo, pero alejados de preocupaciones estéticas formalistas, siguieron los ideales de la modernidad de humanismo fotográfico (Henri Cartier-Bresson y compañía)15. Así, si bien sus obras abordan problemáticas inherentes a la existencia socia del ser humano, no lo hacen siguiendo los códigos estéticos y éticos del fotógrafo como

Bolaños y Juan Javier Salazar; y por colectivos como E.P.S. Huayco (1980-1981) y Taller NN (1988-1991).

15 Augusto del Valle y Juan Mendoza Montevideo (2020) han mostrado que en la misma época en que Secuencia Foto Galería promovía los valores del modernismo formalista, se desarrollaba en Lima un colectivo fotogrático preocupado por el registro de los movimientos sociales de izquierda: Inter-Foto. "testigo de la historia". Así, esta matriz indisciplinada los llevó a desarrollar prácticas fotográficas artísticas que, aunque muy diferentes entre ellas (tanto estética como conceptualmente), comparten una forma de entender la fotografía que vamos a calificar, siguiendo a Rancière (2010, pp. 105-128), como pensativa.

2. LA GENERACIÓN DE LOS "INDISCIPLINADOS": ROBERTO HUARCAYA, FLAVIA MARÍA BEDOYAY JUAN ENRIQUE BEDOYA

12. El objetivo de esta sección no es realizar un examen detallado de los fotógrafos de esta generación -lo que requeriría estudios particulares pormenorizados-, sino establecer algunos factores comunes que hacen de ellos representantes de una misma forma de entender (epistemología) y de usar (performatividad) la imagen fotográfica. Para ello, señalaremos qué problemáticas han explorado, y qué estrategias plásticas y conceptuales han usado para abordarlas. Repasaremos sus 30 años de producción, pero enfatizando la década de 1990, cuando afirman una forma singular de usar la fotografía.

\section{Roberto Huarcaya: en los límites de la} condición humana

13. A pesar de su heterogeneidad temática y formal, se puede afirmar que la obra de Huarcaya, como él mismos lo afirma (2018), tiene como problema central la exploración de los márgenes o de los "límites". Sus proyectos parecen mostrarnos una visión binaria de la existencia al poner en tensión términos como sueño/vigilia, consciente/inconsciente, vida/ muerte, fotografía/pintura, nacimiento/deceso, presente/pasado, figurativo/abstracto, riqueza/pobreza, imagen/texto, recto/verso, loco/ cuerdo, etc. Sin embargo, lo que le interesa a Huarcaya es señalar lo que ocurre entre los opuestos. El "espacio intermedio", como afirma en una entrevista $(2020$, p. 6). Así, intenta llevarnos hacia esos límites trascendentales en los que el "lado B" de la existencia se topa con el " $\mathrm{A}$ ", pero de tal manera que la distinción rígida entre ambos se pone en cuestión. De esta forma, sus obras problematizan diversas maneras en que el ser humano, siempre atravesando 
fronteras y habitando umbrales, enfrenta su condición pasajera, escindida, finita, su ser-enel-mundo (Heidegger, 1993, pp. 53-63) Su obra es una reflexión visual sobre la condición transitoria, fluida, procesual y, por tanto, pasajera, efímera, fugaz, del ser humano. La existencia, en el lenguaje de Deleuze y Guattari (2002) como proceso de re/desterritorialización constante. En sus primeras series -notablemente en Deseos, temores y divanes (1990) y La nave del olvido (1994)- se observa una preocupación por los aspectos psicológicos de la experiencia humana, sin duda debido a su formación como psicólogo. En estas dos series alegóricas, empleando potencias opuestas del dispositivo fotográfico como la puesta en escena y el registro indicial, explora ese límite, o puente, que separa y conecta al mismo tiempo el ámbito de la razón y el del delirio, el de lo normal y el de lo anormal. Esta inquietud se reafirma en los proyectos más ambiciosos que Huarcaya desarrolla en la segunda mitad de los 90, en los que se consagra a reflexionar sobre el fenómeno de la vida y sus relaciones con la muerte: Continuum (1994), Nacimiento-muerte (1994) y El retorno del olvido (1997). Todos estos proyectos son "una exploración sobre las periferias de la vida", como lo escribió Castro (2007, p. 41).

14. Huarcaya ha recurrido a diversas estrategias formales y conceptuales para cuestionar en sus imágenes la experiencia de la disolución de los límites y de los territorios fijos en manos del puro devenir. Así, la teatralización en Deseos, temores y divanes -inspiradas en la obra de Duane Michals, como remarcó Castro (1990)-, muestran un mismo espacio habitado, en distintos momentos, por diversos personajes, reales o fantásticos. Recurriendo a estrategias formales como el barrido o el desenfoque, Huarcaya crea una atmosfera de ensoñación en la que no sabemos si estamos despiertos o dormidos. En sus series posteriores, además de la puesta en escena y la teatralización, Huarcaya se interesa por las impresiones de gran formato y por la experimentación con montajes no convencionales. Estos recursos formales se alejan del medio fotográfico puro con la finalidad de crear, como señalan Majluf y Villacorta (1997, p. 29), dispositivos plásticos orientados a producir una experiencia sensorial compleja. Esta búsqueda se concreta de modo ejemplar en El retorno del olvido, instalación fotográfica con la que Huarcaya participó en la VI Bienal de la Habana (1997). Dicha instalación contó con nueve fotografías de gran formato $(180 \times 120 \mathrm{~cm}$ cada una), impresas por ambos lados y colgadas alrededor de una escalera espiral. Nueve de ellas miran hacia el interior de la escalera, y las restantes hacia el exterior. Todas representan la continuidad y discontinu lad inherentes a las exterior son fotografías de ojos; las del interior, retratos de cuerpos (desde un bebé hasta un anciano) (Villacorta, 1997). Por otro lado, en Espacios soñados, obra expuesta en la Bienal de Venecia de 2001, el fotógrafo nos presenta otra instalación monumental, esta vez recurriendo a tres grandes cajas de luz conformadas por transparencias (20 $\times 25 \mathrm{~cm}$ cada una), dando lugar así a una gran pantalla luminosa (100 $480 \mathrm{~cm}$ ). Cada caja explora -entre abstracción y figuración, entre realismo y surrealismo- una región natural del Perú: la costa, la sierra o la selva. En esta pieza Huarcaya explora formato y formas de representación que nos inviten a mirar y pensar el paisaje peruano -un tema recurrente en las artes visuales nacionales- por fuera de las representaciones icónicas a las que estamos acostumbrados.

15. La obra de Huarcaya ha evolucionado explorando formatos, materiales, procesos y temáticas diferentes Sin embargo, si analizamos sus últimos trabajos, veremos que, sin negar la presencia de otras preocupaciones, la cuestión de la oposición y el pasaje reaparecen puestas al servicio de la problematización (ontológica y epistemológica) de los límites de la representación y, como sugiere Vich, de la naturaleza misma (s/f, p. 4). En Amazogramas (2014), Andegramas (2017), Danzas Andinas (2018), Bosque de Eucaliptos (2018), Océanos (2019) y Cuerpos develados (2017-2021), a través de la construcción de fotogramas monumentales -forma primigenia del proceso fotográficoHuarcaya cuestiona la relación representaciona privilegiada que la fotografía mantiene, supuestamente, con el mundo. Estos fotogramas son por ello, una imagen primera y última, como señala acertadamente Vich (s/f, p. 4).

\section{Flavia Gandolfo: en los lindes de la historia}

16. Flavia Gandolfo no ha seguido el ritmo vertiginoso ni los imperativos implacables de mercado del arte contemporáneo. Gracias ello ha podido explorar meditada y libremente la problemática que atiza su creatividad: los espacios en los que se negocia la constitución de identidades. Sus proyectos exploran lo que Foucault llamó los modos de producción de subjetividad (1990, p. 48). A pesar de esta continuidad, es posible distinguir, como ella misma indica (2018), dos periodos en su producción: en el primero, influenciada por el trabajo de Diane Arbus y de Juan Enrique Bedoya Gandolfo desarrolla una práctica fotográfica directa, cercana al fotoperiodismo y al street photography 16; y se focaliza, temáticamente, en la exploración de los modos de subjetivación no hegemónicos de colectividades disidentes. En estos trabajos tempranos, Gandolfo retrata, de forma muy personal, la vida cotidiana, entre disfrute y decadencia, de dos comunidades marginalizadas: los travestis de los cabarés (Transformismas, 1991-1992) y los peleadores de la lucha libre (Cachascanistas, 1992). En ambos casos, usa la fotografía para contar la historia -una historia al menos- de los sin historia, de grupos humanos subrepresentados $y$ por tanto, sin imagen, sin voz, sin poder y sin capacidad de agencia en el campo social. Los primeros, debido a su identificación sexual y de género; los segundos, al declive de su oficio. Aunque no explícitamente, en estos proyectos se hace patente la formación universitaria de Gandolfo: la Historia. Especialmente su interés por la historia no oficial y de lo no oficial: "(...) había un curso -nos cuenta hablando sobre sus años universitarios- de Historia de la Marginalidad que me fascinó" (2018).

17. Su formación como historiadora se hace aún más evidente cuando Gandolfo retorna al Perú luego de estudiar en Estados Unidos. Entre los años 1996 y 1998 realiza las obras que darán lugar a su primera exposición

16 Gandolfo (2018) cuenta que en el año 1988 una de sus primeras experiencias profesionales fue trabajand como fotoperiodista en un diario local, donde su tare era hacer retratos para el suplemento dominical. Esto influenció sus primeros trabajos personales. individual en la Sala Luis Miro Quesada Garland: "Historia" (1998). En dicha exhibición, se consagró a explorar las relaciones imaginarias entre la Historia oficial del Perú, la educación en centros educativos públicos y la formación de la identidad nacional. Alejada de la fotografía directa, Gandolfo recurre a estrategias de carácter conceptual (apropiación, re-fotografía, instalación, tipología, etc.) para articular su visión del carácter fracturado de nuestro proyecto nación, como han afirmado López (2020, p. 38) y Portocarrero (2020, p. 63). En una de las series que más comentarios generó, El Perú, Gandolfo construye una gran instalación -estableciendo una suerte de tipología heredera de Bernd y Hila Becher- en la que presenta 99 reproducciones fotográficas de páginas de cuadernos con dibujos de mapas del Perú. Gandolfo articula una tipología que da cuenta de la "imagen oficial" del Perú según estudiantes de escuelas públicas. La potencia de esta obra radica en la relación equilibrada entre su minimalismo formal que casi excluye el gesto fotográfico, el sarcasmo que vehiculan la superficie de sus imágenes y el profundo mensaje que transmiten sobre la imposibilidad de construir una identidad nacional unificada. Gandolfo (2018) cuenta que las estrategias formales usadas en esta muestra le valieron, por un lado, el comentario crítico de autoridades como Billy Hare quien parecía no entender porque tenía que fotografiar los cuadernos en vez de, simplemente, fotocopiarlos. Por otro lado, los visitantes reaccionaron preguntándose si "eso" (fotografiar cuadernos) podía ser considerado "arte". Las estrategias formales que Gandolfo incorpora en su trabajo la ubican, al igual que Huarcaya, en un espacio de indisciplinamiento, tanto con relación al sentido común del gran público como al saber especializado del canon modernista. Y es esto, como señala la misma autora (Gandolfo, 2018), lo que le interesaba: "(...) siempre me decía: 'jah! ¿Esa es la norma?, ¿cómo la rompo? ¡Ah! ¿Eso es lo correcto?, ¿y eso cómo se quiebra?".".

18. Así, en series como Las razas (19961998), El Perú (1996-1998), El cuaderno de Nancy (1996-1998) e Historia del Perú (19961998), a través de la articulación conceptual de imágenes ingenuas producidas por niños, Gandolfo manifiesta la violencia inherente a 
nuestra herencia colonial y al abandono sistemático de las poblaciones más vulnerables por parte del Estado. De esta forma, tanto en sus primeros trabajos como en estas series dedicadas explícitamente a la Historia del Perú, Gandolfo usa la fotografía para invitarnos a pensar en los aspectos problemáticos de la construcción de identidad(es) no consideradas por la historiografía oficial, como ha señalado pertinentemente Portocarrero (2020, p. 59). Sus últimos proyectos -presentados en la galería Garúa (2015) y en el Museo de Arte de Lima (2020)-, aún más conceptuales y transdisciplinarios, y recurriendo a estrategias focalizadas en la materialidad y en la procesualidad, indagan en torno a los discursos oficiales que, a través de los libros de Historia canónicos (como el de Pons Musso), han modelado la imagen y la idea que diversas generaciones de peruanos tienen sobre el "Perú".

\section{Milagros de la Torre: en el silencio de los objetos}

19. Milagros de la Torre desarrolló su obra alejada del resto de integrantes de esta generación debido a que ha vivido en el extranjero desde muy joven (principalmente en Inglaterra, México y Estados Unidos)17. Su trabajo ha mantenido a lo largo del tiempo una gran coherencia, tanto desde una perspectiva temática como formal, afirmando así una singular manera de utilizar la fotografía como espacio de cuestionamiento. A pesar de su compromiso con la realidad, las estrategias post-conceptuales a las que recurre no están alineadas con el carácter representacional del realismo fotográfico y se separan, en consecuencia, de la retórica del fotoperiodismo y del documentalismo que poseían la hegemonía de la representación de los acontecimientos sociales en el Perú de los años 80 y 90, como bien ha señalado López (2012, p. 47). Así, en su obra no encontramos

17 Esto no significa, sin embargo, que Milagros de la Torre no haya tenido contacto con la comunidad de fotógrafos que se estaba terminando de institucionalizar y afianzar a inicios de los 90. De la torre (2020) cuenta que, para realizar Bajo el sol negro en el Cusco, debía obligatoriamente pasar por Lima cuando llegaba de Inglaterra. En esas estancias tuvo muchos intercambios con fotógrafos como Billy Hare, Roberto Huarcaya, แ⿰亻 ni representaciones directas ni espectaculares. Sus opciones creativas, a medio camino entre Sus opciones cretivas, a medio camino entre cado, sin embargo, una despolitización (formal abstracta o mercantil). Por el contrario, la total dad de sus proyectos -desde Bajo el sol negro (1991-1993) hasta Intervalos (2020)- nacen del intento de dar a ver los efectos de las relaciones de poder que gobiernan nuestras sociedades.

20. De la Torre es una de las fotógrafas peruanas que ha explorado y reflexionado de manera más inteligente sobre los vestigios y las huellas de las diferentes formas de violencia social que azotan a nuestras sociedades y se marcan en nuestros cuerpos (López, 2012 p. 54)18. Por ejemplo, en su primera y más celebrada serie, Bajo el sol negro, recuperando una técnica fotográfica callejera utilizada por los fotógrafos cusqueños del siglo XIX (los minuteros), pone en evidencia críticamente el proceso de "blanqueamiento" al que dichos fotógrafos sometían a sus conciudadanos. De tal forma como afirman Majluf y Villacorta (1997, p. 31) la artista muestra que la representación fotográfica operaba como una estrategia de "mejora racial" inconscientemente asumida como parte de la herencia colonial. En otras series realizadas en la década del 90, De la Torre continú explorando de forma sugerente, nunca categórica -de ahí la dificultad para descifrar su trabajo (Sullivan, 2012, p. 13)-, diferentes expresiones de violencia cultural: los objetos convertidos en signos silenciosos de tragedias en Los pasos perdidos (1996), la violencia cotidiana que expresan los camiones de seguridad en Blindados (2000), la brutalidad implícita en las vestimentas que aluden al cuerpo de un desaparecido por causa de las dictaduras en Sin título (Los desaparecidos) (1998) y la violencia ejercida a las páginas de libros por la censura de la Inquisición española en Censurado (2000). La sutileza formal y conceptual con la que De la Torre aborda estas problemáticas le permite evadir la representación directa de los eventos violentos y de sus consecuencias traumáticas,

8 Estos años estuvieron principalmente marcados por el Conflicto armado interno que enfrentó al PCP Sendero Luminoso y al Estado peruano. De la Torre vivió muy de cerca este evento historico pues su padre fue parte de policía de inteligencia del Estado. focalizándose, por el contrario, en estrategias para hacer visibles y legibles sus dimensiones un lenguaje analítico para hablar de forma indirecta y tangencial, a veces incluso enigmática, de los fenómenos sociopolíticos que emergen de la violencia inherente a nuestra sociedad (Best, 2016, p. 2).

21. Para ello, Milagros de la Torre recurre estrategias conceptuales de creación y de investigación basadas, principalmente, en la apropiación de archivos (Lopez, 2012, p. 46), gracias a lo cual su obra deviene un "contra-archivo" crítico (Merewether, 1999, p. 1). Tal vez esto es una herencia de la profesión de su padre. Probablemente, de ahí proviene el deseo de leer los signos ocultos en los objetos, y de hacer hablar a las cosas aparentemente silenciosas (Sullivan, 2012, p. 22 y Olivares, 2000) para "nombrar lo no nombrado, lo no señalado, lo no firmado" (Merewether, 1999, p. 6). En tal sentido, no aborda directamente los eventos de la historia, sino que usa la fotografía para mostrar los vestigios que insisten de forma latente en los objetos que restan de dichas historias. Esto se aprecia en varias series como Sin título (percha, medias) (1992), Incrustado (2007), A prueba de balas (2008), El final (cianuro) (2008) y Sin título (cascos) (2009). Debido a ello, sus trabajos son doblemente indiciales: su fotografía es un índice de la singularidad del objeto fotografiado. Este, a su vez, no solo representa icónicamente un tipo particular de objeto (casco, media, camisa, etc.), sino que encarna indicialmente la singularidad de una experiencia vivida (la de policía que portó dicho casco, la de la mujer que usó aquellas medias, la del guardaespaldas que llevó aquella camisa, etc.). Este interés por la potencia significante del archivo, por su capacidad de conectar los traumas singulares con lo histórico y con lo universal (Sullivan, 2012 p. 14), lleva a De la Torre a utilizar pequeñas series fotográficas no narrativas. En algunos casos dos o tres imágenes son suficientes para transmitir la potencia simbólica de un evento (la depresión, la violencia política, la inseguridad ciudadana), como en el caso de El final (cianuro) y $\operatorname{Sin}$ título (Desaparecido). En otros casos, recurre a series más largas, pero nunca narrativas sino, más bien, reiterativas como en el caso de Blindado, Incrustado, A prueba de balas y Sin título (cascos). En estos ejemplos, como también sucede en Los pasos perdidos, De la Torre trabaja con objetos encontrados, usando la fotografía como un medio para transformar estos objetos cotidianos, banales, aunque cargados de historia, en espacio de proyección imaginaria y de inquietud para el pensamiento. La totalidad de su trabajo sigue esta línea de investigación, como se ve en su último proyecto, Intervalos, un diaporama donde, a partir de imágenes de archivo, muestra el control ejercido sobre los individuos con el uso de técnicas para identificar los rostros (desde la antropometría de Bertillon hasta los sistemas de reconocimiento facial actuales).

\section{Luz María Bedoya: en la fragilidad del sentido}

22. Tal vez Luz María Bedoya sea la más indisciplinada de esta generación de "fotógrafos". Es la que más ha derivado, o delirado, en sus procesos creativos, abandonando la especificidad del medio fotográfico, como sostiene Bernuy (2016, p. 172), pasando de un medio a otro o combinándolos según las necesidades de cada proyecto y sus propias inquietudes. Ha trabajado con la imagen fotográfica, desde luego, pero también con el video, el sonido, la escritura, la performance, la instalación o el dibujo, lo que la ubica más cerca de las prácticas artísticas contemporáneas que de la fotografía (Villacorta, 2014, p. 1 y Biczel, 2014, p. 2). Temáticamente, su trabajo reflexiona en torno al estatuto de las relaciones entre el sujeto, los signos y las cosas. Bedoya se interesa por ese punto en el que el proceso de significación falla y se revela el sin-sentido que habita en el centro toda producción de sentido. En lenguaje lacaniano, explora las dinámicas en las que el imaginario agrieta lo simbólico permitiendo que emerja lo real. Por ello Biczel $(2014$, p. 7) ha señalado que su trabajo gira en torno a la "insignificancia de lo real", sobre esa dimensión de la existencia que emerge silenciosa desde el fondo de nuestra realidad verídicamente cualificada con categorías binarias significantes, como diría Nietzsche (1989). La fotografía ha sido una herramienta clave en sus primeros proyectos porque gracias a su carácter indicial le ha servido para intentar tocar ese real-singular aparentemente a-significativo. Así, su obra 
está conformada por significantes que buscan significar, pero que fracasan en el intento. Su obra es, como afirma López, una "práctica de desvío" $(2014$, p. 2) que "se empeña en simbolizar esa condición errante del sentido" (2014, p. 3). Bedoya aborda su problemática, al igual que De la Torre y que Gandolfo, de forma sobria. Su presentación del vacío del ser no es ruidosa; sutil, se presenta como esa "inquietante extrañeza" (Freud, 2006) que habita en nuestro entorno más cercano cuando lo miramos con ojos des-familiarizados.

23. Su primer proyecto importante, la foto-instalación Punto ciego (1997) -una de las primeras propuestas de esta naturaleza en la escena peruana (Bernuy, 2016, p. 173)-, demuestra esta última afirmación. La instalación estuvo compuesta por 70 fotografías tomadas con una cámara panorámica descartable y realizadas desde la ventana de un vehículo en la carretera. Colgadas en línea recta marcando un horizonte continuo, las imágenes muestran puntos aleatorios, ordinarios, insignificantes, de la Panamericana. Nada en ellas nos permite captar la grandeza geográfica del territorio, ni su majestuosidad cultural; tampoco se afirman como expresión simbólica de su visión, ni como exploración formal de cualidades fotográficas. Lo que vemos en dichas fotografías es el registro repetitivo, intrascendente, de un recorrido singular. El mismo espíritu está presente en obras como Pircas (1998) y Área (2000-2012) en las que nos enfrentamos a la tautología de referentes incapaces de significar más allá de sí mismos. En otros proyectos de la misma época, Bedoya prolonga su obsesión por mostrar que todo sentido está habitado por un sin-sentido, pero que eso no significa, necesariamente, hundirse en la noche oscura del caos, sino abrir la posibilidad para la emergencia de otros sentidos por fuera del buen-sentido y del sentido-común, como diría Deleuze (1969, pp. 92-101). Así, produce cartografías improbables cargadas de un sentido paradójico que no se identifica con el "sentido funcional" que hace operar al orden simbólico (y al sistema social), sino con eso que podríamos llamar un "sentido poético" que agrieta al orden simbólico redistribuyendo, usando las palabras de Rancière (2009, p. 9), lo sensible. La obra Plano (2001), recorrido tan singular sobre la ciudad que podría ser cualquiera y, por tanto, universal. En a obra Afuera (2001) recurriendo a un trabajo de creación colaborativa, Bedoya reparte cámaras descartables a viajeros con la indicación de fotografiar arbitrariamente un tramo (in)determinado de su viaje. De ello resultan cortes de espacio y del tiempo arbitrarios, espacios de transición que dan cuenta de un desplazamiento cualquiera sobre una ciudad cualquiera. De a misma manera, estos métodos para deshacer las formas hegemónicas de cartografiar y significar una ciudad aparecen en proyectos como Muro (2001) y Volantes (2002) en los que Bedoya, abandonando la fotografía y recurriendo a estrategias textuales, performativas y relacionales, deconstruye el sistema de signos que compone el lenguaje verbal. Ya sea desarticulando una frase de uso común en el transporte público para reinsertarla fragmentada en el flujo de peatones (Volantes), o escondiendo pequeños papeles con frases que respetan la gramática de una lengua, pero que no forman ninguna frase con sentido (Muro), en ambos casos asistimos a micro gestos que tienen como objetivo poner en jaque nuestra posibilidad de hacer sentido en y con el lenguaje. Por lo tanto, confrontamos acciones que ponen en cuestión nuestra propia naturaleza en tanto animales lingüísticos. Estas obras marcan con claridad el hecho de que el medio fotográfico terminaría siendo, como sostuvo López $(2014$, p. 3) una herramienta entre otras para explorar y reflexiohar en torno a la operatividad de los signos, esto es, un "instrumento proyectual" (Radulescu de Barrio de Mendoza, 2016, p. 310).

24. A lo largo de los años Bedoya ha desarrollado dichas prácticas conceptuales recurriendo, entonces, a una gran economía y a una rica pluralidad de medios 19 con el objetivo de producir dispositivos estéticos que pongan a sus espectadores ante el desafío de tener que descifrar su (sin)sentido latente. De ahí que su trabajo exprese, según Villacorta, una "condición post-medio" (2014, p. 2). Así, recurriendo

19 Bedoya (2018) confiesa que su poca habilidad técnica le ha permitido usar los materiales de forma hibre y experimental para explotar al máximo su potencial (a)significante. al video y al dibujo en Línea de Nazca (2008) Bedoya nos invita a re-pensar nuestra relación con el horizonte y a re-definir el imaginario que tenemos de las líneas de Nazca, confrontando la visión aérea englobante común con la visión al ras fragmentaria propuesta por la artista. Sus últimos trabajos, notablemente Transporte plástico sobre la construcción de una ciudad (2018) performance efímera realizada a partir del texto homónimo de Jorge Eduardo Eielson (1954), muestran que la preocupación de Bedoya en torno al carácter fugaz y evanescente del sentido; $y$, sin embargo, imprescindible y urgente, sigue guiando sus exploraciones artísticas.

\section{Juan Enrique Bedoya: en el delirio de los archivos}

25. Juan Enrique Bedoya es el primero de su generación que comenzó a trabajar activamente con la fotografía en la segunda mitad de los años 80. Gandolfo (2018) y Luz María Bedoya (2018) afirman que la figura de Bedoya fue determinante en sus años de formación pues él les compartía no solo su experiencia práctica y técnica, sino principalmente sus referentes y conocimientos ligados a la historiayla teoría de la fotografía Ambas artistas señalan que una de las influencias importantes de su trabajo inicia fue Diane Arbus, quien les había sido presentada, precisamente, por Juan Enrique Bedoya. Los primeros trabajos de Juan Enrique Bedoya tambien estilo "street" y la atracción por los personajes marginales fue parte de sus preocupaciones iniciales. Sus retratos poco ortodoxos de personajes callejeros, y sus series sobre los locales de carretera y los monumentos -en los que se observa la influencia del "estilo documenta" de Walker Evans- muestran ese interés fundamentalmente fotográfico por captar de manera directa, indicial, el carácter singular de una real dad concreta. A pesar de que estuvo cerca de la generación de Secuencia, no adoptó el canon formalista y simbolista. Bedoya, tal vez movido por la violencia de lo real que vivía la generación de los 80 , estuvo más interesado en retratar la forma en que la calle y la ciudad se presentaban ante sus ojos. En tal sentido, comparte con la fotografía documental de la época -con autores como Schwarz y Rázuri- la urgencia de dar a ver la realidad social. Sin embargo, su mundo no era aquel que estaba atravesado por el gran acontecimiento, y su función como fotógrafo no estaba definida por la ética y la estética del testigo de la Historia. Bedoya se ubicaba en un espacio discursivo (Krauss, 2002, pp. 40-59) distinto al del fotoperiodista, al del reportero gráfico y al del documentalista. Su misión, como la de un "chiffonnier" de la historia (Benjamin, 2000) fue recuperar los residuos, las historias marginales, ya sea la de los personajes anónimos, la de los héroes olvidados o la de los restaurantes abandonados.

26. Esta atracción por los márgenes de la historia va a marcar su interés por el archivo, como lo demostraron La fuente de Ameles (1995-1996) y Esmeralda S/S (1997). Estos proyectos resultan, a mi juicio, aquellos que marcan el ingreso directo del trabajo de Bedoya al ámbito expandido o indisciplinado de la creación fotográfica contemporánea. Son obras que rompen completamente, al igual que lo hizo Gandolfo en Historia, Luz María Bedoya en Punto ciego, De la Torre en Bajo el sol negro y Huarcaya en Espacios soñados, con el formalismo, el expresivismo y el simbolismo del tardo modernismo, pero también con el realismo objetivista del documentalismo. La Fuente de Ameles es una instalación fotográfica conformada por 600 piezas hechas de cartón $(18 \times 20 \mathrm{~cm}$ cada una) que contenían la fotografía (blanco y negro) de un objeto -presumiblemente tomada con una cámara estenopeica- y un texto. Entre imagen y texto reina la heterogeneidad, haciendo imposible que este último cumpla la función de ancla (Barthes, 1986). En tal sentido, la pieza, en vez de invitarnos a determinar un sentido coherente que nos permita comprender lo que vemos y leemos, nos pone en una situación de disonancia cognitiva propia de un proyecto artístico consciente de que su objetivo no es mostrarnos una dimensión de la realidad sino hacernos pensar a partir de la experiencia perceptual y sensible que nos ofrece. Un año después, Bedoya construye la pieza S/S Esmeralda (1977), en la que recurre a estrategias similares (imagen y texto), pero esta vez añade un gesto que en el contexto local de aquella época aún podía ser considerado transgresor: las fotografías han sido obtenidas de álbumes comprados en mercados de pulgas. Esto lo alejó aún más del canon purista de la fotografía y lo aproximó, al mismo tiempo, a 
prácticas artísticas contemporáneas en las que la imagen fotográfica no vale por sí misma sino en función de lo que el artista haga con ella al interior de un sistema de signos. Tal vez por ello esta obra obtuvo el primer premio en la Primera Bienal Nacional de Lima (1997) y en el primer concurso de artes visuales Pasaporte para un Artista (1998).

27. A lo largo de más de 30 años hay dos aspectos recurrentes en la obra de Bedoya: desde una perspectiva conceptual, ha buscado poner en cuestión el estatuto objetivo de la representación, invitándonos a dudar de la veracidad de lo que vemos e, incluso, a reconocer que toda imagen, incluso la fotográfica, no es más que una ficción. En tal sentido, su obra tiene un carácter autorreflexivo: usa el medio de la imagen para pensar sobre las posibilidades representacionales de la imagen. Desde una perspectiva temática, Bedoya es una suerte de archivista o coleccionista fuera de lo común. Pareciera que está obsesionado por construir atlas de objetos, pero recurriendo a clasificaciones delirante al estilo de George Perec. Esto ya se apreciaba en las series antes mencionadas, La fuente de Ameles y Esmeralda S/S, y se confirma en sus últimas dos exposiciones importantes: Mecánico Juan (2015) y Museo (2018). Bedoya también ha desarrollado un trabajo como curador realizando exposiciones como El show de Diana (ll Bienal de Fotografía) de Lima, 2014) y Détour (Lima Photo, 2016) en las que se evidencia su interés por los usos alternativos y experimentales de la fotografía.

A MODO DE CONCLUSIÓN: LA OBRA DE ARTE COMO DISPOSITIVO ESTÉTICO DE PENSATIVIDAD

28. El análisis realizado nos permite extraer algunas conclusiones provisorias sobre la singular forma en que la "generación de los indisciplinados" utilizó la fotografía:

El objetivo de sus obras no es "dar a ver". A contracorriente de la tradición representacional hegemónica, estos artistas entienden la imagen fotográfica como un espacio crítico para problematizar algún aspecto de la realidad. No usan la imagen para comunicar un mensaje visual, sino para evidenciar las tensiones, paradojas fracturas que habitan en nuestro orden simbólico.

En tal sentido, sus obras no están hech para ser contempladas, sino para ser le das. Pero no en el sentido restringido del lenguaje verbal, sino en un sentido amplio como cuando decimos, por ejemplo, que un jeroglifo o un síntoma albergan un significado que es potencialmente descifrable, leíble. A los espectadores les corresponde descubrir dicho código de acceso para comprender su dinámica de significación. Por ello, estas obras no están dirigidas a satisfacer solo expectativas perceptuales, sensoriales y afectivas, sino también intelectuales y cognitivas.

Estas obras muestran que la imagen fotográfica autónoma es incapaz de ayudarnos a comprender la complejidad de un fenómeno. Por ello, se concibe como un signo potencialmente significante solo en tanto pertenece a sistemas donde acompaña a otros elementos visuales o no visuales (textos, diseños, sonidos, objetos, etc.). El sentido de estos dispositivos estéticos (Déotte, 2012) reside en las conexiones entre sus elementos: en lo que ocurre en tre las imágenes, entre ellas y el lenguaje verbal que las nombra, entre ellas y los objetos que las acompañan, entre ellas y la realidad que designan, entre ellas y el espacio que las acoge, entre ellas y el espectador que las experimenta, etc.

El carácter cognitivo e instalativo de estas obras implica que el espectador ya no es un sujeto pasivo que contempla desde una posición de exterioridad la obra que se erige frente a él bajo la modalidad del objeto cerrado; sino, más bien, que el espectador activa el dispositivo con su presencia. Gracias a ello se rompe la dicotomía sujeto-objeto y el espectador se convierte en una pieza clave del dispositivo: aquella que permite su autoconciencia llevándolo asi al ámbito del discurso y, con ello, al de la intersubjetividad.
Estos dispositivos estéticos constituyen, por tanto, laboratorios que invitan al espectador a realizar una experiencia compleja (perceptiva, afectiva, sensorial memorística, imaginativa e intelectual) de la problemática que sugieren a través de su materialidad significante. En contacto con estos dispositivos los espectadores realizan experiencias extra-ordinarias que bajo las condiciones que configuran el reparto de lo sensible hegemónico, son inaccesibles. Por ello, se puede concluir que la principal función performativa de sus proyectos es activar procesos de disonancia cognitiva en sus experimentadores, es decir, "dar a pensar".

29. La caracterización que hemos hecho de las obras de los "indisciplinados" nos invita a esbozar una definición del espacio de enunciación desde el que crean y piensan el mundo. Como hemos visto a lo largo del artículo, estos fotógrafos no pertenecen al territorio de la fotografía directa. Pero, esto no significa que no se preocupen por las dimensiones formales documentales de la fotografía. Por el contrario, les interesa mucho la singular relación que la

\section{REFERENCIAS BIBLIOGRÁFICAS}

Alloway, L. (1970). Artists \& photographs. New York: Published by Multiples, Inc., in association with Colorcraft, Inc.

Baudelaire, Ch. (1996). "El público Moderno y la fotografía". En Salones y otros escritos sobre arte, Madrid: Visor.

Baker, G. (2005). "Photography's Expanded Field", En October, num. 114, Massachusetts, otoño.

Barthes, R. (1986). "El mensaje fotográfico". En Lo obvio y lo obtuso. Barcelona: Paidós.

Bedoya, L.M. (2006). "A propósito del conversatorio en el MALI -Sobre fotografía: Una autonomía esquiva-". [Versión web disponible en: https:// bit.ly/3x1/gcb].

Bedoya, L.M. (2014). "La pluralidad de lo fotográfico. Texto publicado en la columna de Alonso Almenara en La Mula, junio. [Versión web disponible en: https://bit.ly/3zyB086].

Bedoya, L.M. (2018, octubre). Entrevista a profundidad [Audio]. imagen técnica establece con lo real, por ello buscan articular dicha potencia indicial a través de nuevas formas de lenguaje visual que les permitan explorar y reflexionar sobre la realidad superando la despolitización del formalismo y el carácter ingenuo del documentalismo clásico.

30. Los indisciplinados están más cerca, por ello, de la figura del artista en el paradigma contemporáneo: usan la imagen como medio, material, herramienta, vector, pretexto, etc., para materializar un pensamiento. Este vínculo con la práctica artística contemporánea, sumado a su herencia académica, nos permite afirmar a modo de hipótesis que estos fotógrafos son representantes de la figura del "artista como investigador". Dicha caracterización se refuerza, asimismo, si tenemos en cuenta que también se han dedicado a la pedagogía. Esta figura que articula la triada creación-investigación-educación, concibe el arte ya no como el proceso de producción de objetos (para la contemplación estética o para el mercado), sino como la exploración de una dimensión de la realidad destinada a generar un conocimiento capaz de redefinir los vínculos sociales. •
Belting. H. (1987). The End of the History of Art. Chicago: University of Chicago Press.

Bernuy, C. (2016). "La idea sólida: la fotografía y su desplazamiento del lugar específico. Conversaciones con Luz María Bedoya y Miguel Aguirre". En Revista Kaypunku, Volumen 3, Número 1, Junio, pp. 167-218.

Benjamin, W. "Un marginal sort de l'ombre". En Æuurres II, Paris: Gallimard.

Best, S. (2016). "Chapter 6: Our Dark Side: Milagros de la Torre's The Lost Steps". En Reparative Aesthetics: Witnessing in Contemporary Art Photography, Best, S. (ed.). Sydney: Bloomsbury. [Versión web disponible en: https://bit.ly/2UC66x7].

Biczel, D. (2014). "De un Punto Ciego a Línea[s] [ln] visibles". En Líneas, palabras, cosas. Catálogo de la exposición de Luz María Bedoya en la ll Bienal de Fotografía de Lima. Lima: ICPNA. [Versión web disponible en: https://bit.ly/3BDxwDd]. 
Biczel, D. (22017). "Sobre la imposibilidad de trazar un mapa: el "fracaso" de la Bienal de Lima (1997-2002)". En: Caiana. Revista de Historia del Arte y Cultura Visual del Centro Argentino de Investigadores de Arte Centro Argentino de Investigadores de Arte (CAIA), numero 11, segundo semestre. [Versión web disponible en: https://bit.ly/2ULgZfN].

Castro, F. (1990). "Sobre el diván: Huarcaya". En Diario El Comercio, Lima, octubre.

Castro, F. (2007). "Roberto Huarcaya. The Ship Sails On". En Revista Aperture \#187, mayo.

Chevrier, J.F. (2003). "The adventures of the picture form in the history of photography". En Fogle, D. (ed.). The Last Picture Show: Artists Using Photography 1960-1982. Minneapolis: Walker Art Center, pp. 113-128.

Crimp, D. (1977). Pictures. Artist Space. Catálogo de la exposición. [Versión web disponible en: https:// bit.ly/2TCnIbA].

Cruz, P. del Valle, A., Hernández Calvo, M., Ramos, H. (2014). "El auge del arte fotográfico". En: Arte Moderno, Kusunoki, R. y Wuffarden, L.E. (eds.). Lima: Museo de Arte de Lima.

Cruz, P. del Valle, A., Hernández Calvo, M., Ramos, H. (2014). "El modernismo fotográfico", En: Arte Moderno, Kusunoki, R. y Wuffarden, L.E. (eds.). Lima: Museo de Arte de Lima.

Danto, A. (1999). Después del fin del arte. El arte contemporáneo y el linde de la historia. Buenos Aires: Paidós.

De la Torre, M. (2020, octubre). Diálogo en Workshop [Audio].

Del Valle, A. (1999). "Memoria sin territorio". En Hueso Húmero, Lima, número 34, pp. 86-120.

Del Valle, A. y Mendoza Montevideo, J. (2020). InterFoto (1979-1980). Memoria y fotografía social: la irrupción de un nuevo sujeto. Lima: Universidad Nacional Mayor de San Marcos.

Del Valle, A. y Villacorta, J. (2002). "Otra actualidad. Las artes plásticas en Perú". En Ars Nova, Madrid, número 01-02, pp. 15-23.

Del Valle, A. y Villacorta, J. (1999). "Las artes visuales de los '90. Zapping y deslizamientos". En Cuestión de Estado, Lima, número 24, pp. 65-70.

Deleuze, G. (1969). Logique du sens. París: Gallimard. Deleuze, G.y Guattari, F. (1978). Kafka, por una literatura menor. México D.F.: Ediciones era.

Deleuze, G.y Guattari, F. (2002). Mil mesetas. Capitalismo y esquizofrenia 2. Valencia: Pre-textos.
Déotte, J. L. (2012). ¿Qué es un aparato estético? Benjamin, Lyotard, Rancière. Santiago de Chile: Metales pesados.

Freud, S. (2006). "Lo ominoso". En Obras completas, vol. xvii, pp. 215-252. Buenos Aires: Amorrortu.

Foucault, M. (1990). Tecnologías del yo. Paidós, Barcelona.

Fried, M. (2013), Pourquoi la photographie a aujourd'hui forcé d'art? Malakof Cedex: Éditions Hazan.

Gandolfo, F. (2018, octubre). Entrevista a profundidad [Audio].

Gras Balaguer, M. (1999). "Especies de espacios. Extensiones y metáforas de la fotografía contemporánea en Perú". En Especies de espacios. Extensiones y metáforas de la fotografía contemporánea en Perú [Catálogo]. Madrid: Argentina: PROM PERÚ: Telefónica, s/n.

Hare, G. y Montalbetti, M. (1977). "Presentación". En Secuencia textos, número 01, julio.

Heidegger, M. (1993). Serytiempo. México D.F.: Fondo de Cultura Económica.

Heinich, N. (2014). Le paradigme de l'art contemporain. Structures d'une révolution artistique. Paris: Gallimard.

Hernández Calvo, M. y Villacorta, J. (2002). Franquicias imaginarias. Lima: PUCP.

Huarcaya, R. (2018, octubre). Entrevista a profundidad [Audio].

Huarcaya, R. (2020). "La nave de la vida". Entrevista en a Revista PerúFoto. Número 3, julio.

Kahmen, V. (1974). La photographie est-elle un art ? Vanves: Editions du Chêne.

Krauss, R. (2002). "Los espacios discursivos de la fotografía". En Lo fotográfico. Por una teoría de los desplazamientos. Barcelona: Gustavo Gili, pp. 40-59.

Kuspit, D. (2006). El fin del arte. Madrid: Akal.

Lerner, S. (2020). "Introducción a un recorrido". En De un punto a otra parte. Catálogo de la exposición de Flavia Gandolfo. Lima: MALI.

López, M. A. (2020). "Extraviar las identidades. Desaceleración y fugaz en la fotografía de Flavia Gandolfo". En De un punto a otra parte. Catálogo de la exposición de Flavia Gandolfo. Lima: MALI.

López, M. A. (2014). "La mínima habla". En Líneas, palabras, cosas. Catálogo de la exposición de Luz María Bedoya en la ll Bienal de Fotografía de Lima. Lima: ICPNA. [versión web disponible en: https://bit.ly/3BDxwDd].

López, M. A. (2012). "Outside the Life of the Body". En Observed. Catálogo de la exposición de Milagros de la Torre. Lima: MALI.
Majluf, N. "Bajo el sol negro". Lima: Centro Cultural de la Municipalidad de Miraflores, 1994. IVersión web disponible en: https://bit.ly/2TwqJKk].

Majluf, N. (2006). Sobre fotografía. Una autonomí esquiva. Lima: Museo de Arte de Lima.

Majluf, N., Wuffarden, L.E., Schwarz, H., Benavente, A. (2001). El primer siglo de la fotografía: Perú 1842 1942: La recuperación de la memoria. Lima: .

Mariátegui, J. C. y Zegarra, M. (2000). "Vía Satélite. Panorama del video y la fotografía en el Perú contemporáneo". En Vía Satélite: Panorama de la fotografía y el video en el Perú Contemporáneo [Catálogo de exposición]. Lima: Fundación Telefónica, pp. 9-21. [Versión web disponible en: https://bit.ly/2TxqrD0].

Mariátegui, J. C. y Zegarra, M. (2000). "TecnoRevolución: ¿Falsa Evolución?". En Márgenes: Encuentros y debates. Lima, año XIV, número 17, pp. 127-140. [Versión web disponible en: https:// bit.ly/3y $5 \mathrm{~m} / \mathrm{Rt}]$.

Merewether, Ch. (1999). "The Fate of Things to Come" En Milagros de la Torre: Fotografía, Arriola, M. (ed.). México D.F.: Museo de Arte Carrillo Gil. [Versión web disponible en: https://bit. ly/2W8n3PS]

Montalbetti, M. (1980). "Sobre la fotografía peruan actual". En Hueso Húmero, número 5/6, abrilseptiembre, Lima, pp. 90-97.

Nietzsche, F. (1989). Crepúsculo de los ídolos o como se filosofa a martillazos. Madrid: Alianza editorial.

Olivares, R. (2000). "Milagros de la Torre". En El Enigma de lo cotidiano. Madrid: Casa de Américas.

Portocarrero, F.(2020). "Flavia Gandolfo. La interpelación histórica". En De un punto a otra parte. Catálogo de la exposición de Flavia Gandolfo. Lima: MAL

Quijano, $R$ (2002). "¿De qué puntos cardinales hablan? Anotaciones sobre la última década en las artes peruanas". En Puntos Cardinales - 4 artistas visuales peruanos, Lima: Quidam, pp. 10-18.

Quijano, R. (2013). "Notas incompletas sobre el sitio de la fotografía peruana". En Arte Contemporáneo. Colección Museo de Arte de Lima, Lerner, S. (ed.) pp. 47-61. Lima: Museo de Arte de Lima.

Radulescu de Barrio de Mendoza, M. (2016). "Luz Marí Bedoya. Líneas, palabras, cosas. Lima: Instituto cultural Peruano Norteamericano, 2014". En Revista Kaypunku, volumen 3, número 1, junio, pp. 305-315.

Rancière J. (2010). El espectador emancipado. Buenos Aires: Manantial.
Rancière, J. (2009). El reparto de lo sensible. Estéticay política. Santiago: LOM Ediciones.

Rouillé, A. (2005). La photographie. Entre document et art contemporain. Paris: Gallimard.

Sekula, A. (2004). "Desmantelar la modernidad, reinventar el documental. Notas sobre la política de la representación". En Ribalta, J. (ed.). Efecto real. Debates posmodernos sobre fotografía. Barcelona: Gustavo Gili

Scharf, A. (1968). Art and Photoraphy. Londres: The Penguin Press.

Sullivan, J. (2012). "Silent Witness: The Photographic Art of Milagros de la Torre". En Observed. Catálogo de la exposición de Milagros de la Torre. Lima: MALI.

Smith, T. (2012). ¿Qué es el arte contemporáneo? Ciudad de México: Siglo Veintiuno Editores.

Solomon-Godeau, A. (2004). "Imágenes convencionales". En Efecto real. Debates posmodernos sobre fotografía. Ribalta, J. (ed.). Barcelona: Gustavo Gili, pp. 186-193.

Trivelli, C. y Villacorta, J. (2014). Catálogo de la Il Bienal de Fotografía de Lima, Lima: Centro de la Imagen.

Vich, V. (s/ff). "Fotografiar sin cámara: el arte sublime de Roberto Huarcaya". [Versión web disponible en: https://bit.ly/3zyBLxY]

Villacorta, J. (1997). "El Retorno del Olvido". Texto del folleto de Roberto Huarcaya para la VI Bienal de La Habana, Cuba. [Versión web disponible en: https://bit.ly/3hZQ8FN].

Villacorta, J. (2014). "Un haz de líneas que incide en lo contingente". En Líneas, palabras, cosas. Catálogo de la exposición de Luz María Bedoya en la ll Bienal de Fotografía de Lima. Lima: ICPNA.

Wall, J. (2003). "«Señales de indiferencia». Aspectos de la fotografía en el arte conceptual como arte conceptual". En Wall, J. Ensayos y entrevistas. Salamanca: Centro de Arte de Salamanca, pp. 275-312.

Zevallos Trigoso, C. (2016). La resistencia de la imagen fotográfica: prácticas y discursos artísticos en la fotografía limeña contemporánea. Tesis para optar por el grado de Magister en Antropología Visual. Lima: Pontificia Universidad Católica del Perú. Asesora: Giuliana Borea. Miembros del jurado: María Eugenia Ulfe, Valeria Biffi y Giuliana Borea. 